\title{
Highly Sensitive LC-MS/MS Method for Determination of Memantine in Rat Plasma: Application to Pharmacokinetic Studies in Rats
}

\author{
Suresh P S 1 , Ramesh Mullangi ${ }^{2}$ and S Sathesh Kumar ${ }^{1^{*}}$ \\ 1'Department of Pharmaceutics, School of Pharmaceutical Sciences, Vels Institute of Science Technology and Advanced Studies \\ (VISTAS), Vels University, Chennai-600117, India \\ 2Jubilant Biosys Ltd, Industrial Suburb, Yeshwanthpur, Bangalore-560022, India
}

\begin{abstract}
Background: A rapid and highly sensitive assay method has been developed and validated for the estimation of memantine (MEM) in rat plasma using liquid chromatography coupled to tandem mass spectrometry with electro spray ionization in the positive-ion mode. Method validation was performed as per United States Food and Drug Administration (US FDA) guidelines. Methods: The assay procedure involves a simple liquid-liquid extraction of MEM and phenacetin (internal standard, IS) from rat plasma using methyl tert-butyl methyl ether. Chromatographic separation was achieved with $0.2 \%$ formic acid: acetonitrile $(40: 60, \mathrm{v} / \mathrm{v}$ ) at a flow rate of $0.50 \mathrm{ml} / \mathrm{min}$ on an Atlantis dC18 column with a total run time $3.0 \mathrm{~min}$. The MS/MS ion transitions monitored were 180.10 ® 163.30 for MEM and $180.10{ }^{\circledR} 110.10$ for IS. Results: The results met the acceptance criteria mentioned in the guidelines. The lower limit of quantitation achieved was $0.025 \mathrm{ng} / \mathrm{ml}$ and the linearity was observed from 0.025 to $220 \mathrm{ng} / \mathrm{ml}$. The intra- and inter-day precision was in the range of $0.88-6.84$ and $2.57-6.79 \%$, respectively. Conclusions: An LC-ESI-MS/MS for the determination of MEM in rat plasma employing simple liquidliquid extraction was developed and validated with high sensitivity and selectivity. This novel method has been applied to a pharmacokinetic study in rats.
\end{abstract}

Keywords: Memantine, LC-MS/MS, Method validation, Rat plasma, Rat brain, Rat CSF, Pharmacokinetics.

\section{INTRODUCTION}

Memantine (MEM; CAS no: 19982-08-2); (Figure 1), chemically 3,5-dimethy-ladamantan-1-amine or 3,5-dimethyl tricyclo[3.3.1.1] decan-1 amine belongs to a class of drugs known as non-competitive antagonist at glutamatergic N-methyl-D-aspartate (NMDA) receptors. ${ }^{1}$ MEM is used in the treatment of moderate to severe Alzheimer's disease. ${ }^{2}$ It acts by blocking the NMDA receptors by acting on glutamatergic system. ${ }^{3}$ Namenda $\mathrm{XR}^{\circledR}$ (memantine hydrochloride extended release) is commercially available as tablets (5 and $10 \mathrm{mg}$ ), extended release capsules (7, 14, 21 and $28 \mathrm{mg})$ and oral solution $(2 \mathrm{mg} / \mathrm{ml})$. Following oral administration, this drug completely absorbed in gastrointestinal tract and its absorption is not affected by food. Following single oral dose of MEM (20 $\mathrm{mg}$ ), the peak plasma concentrations $\left(\mathrm{C}_{\max }: 24-29 \mu \mathrm{g} / \mathrm{L}\right)$ achieved at about 3.3$6.0 \mathrm{~h}\left(\mathrm{~T}_{\max }\right)$ in fasted condition. Its protein binding was found to be $\sim 45 \%$. MEM undergoes metabolism via hydroxylation, $\mathrm{N}$-oxidation and conjugation to inactive metabolites. In vitro studies suggest that there is no involvement in the CYP450 enzymes for biotransformation of MEM. The mean terminal half-life $\left(t_{1 / 2}\right)$ is around 60-80 h. MEM and its metabolites are primarily eliminated through urine (75-90\%) and the remaining recovered through bile and feces. ${ }^{4,5}$

Majority of the LC-MS/MS methods have been reported for estimation of MEM in clinical studies ${ }^{6-12}$ and one method to support preclinical study. ${ }^{13}$
Submission Date :21-05-14 Revision Date : :18-08-14 Accepted Date : 03-09-14

DOI: $10.5530 /$ ijper.48.4.8

Address for correspondence:

Dr. S. Sathesh Kumar

Department of Pharmaceutics, School of Pharmaceutical Sciences, Vels Institute of Science Technology and Advanced Studies (VISTAS), Vels University, Chennai-600117, India Phone: +91-9551412737 E-mail: sathesh2000@ gmail.com

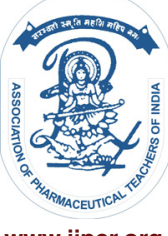

www.ijper.org 


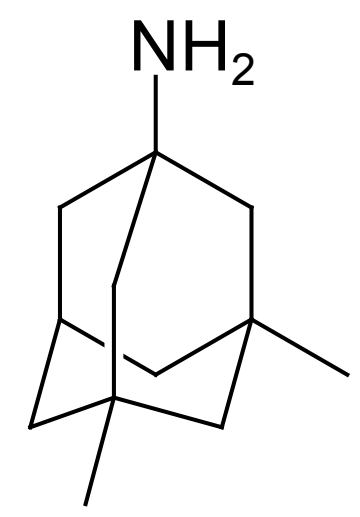

Memantine (MEM)

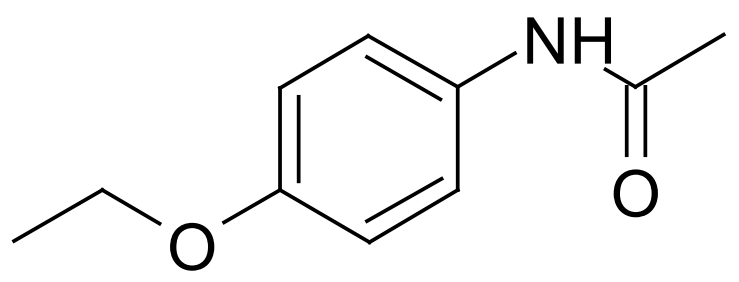

Phenacetin (IS)

Figure 1. Structural representation of memantine (MEM) and IS

Among these methods the lowest reported lower limit of quantification (LLOQ) was $0.05 \mathrm{ng} / \mathrm{ml}$ using $100 \mu \mathrm{l}$ plasma. ${ }^{6}$

In a preclinical set up, especially with rodents, only small volumes of blood $(\sim 50-100 \mu \mathrm{l})$ can be drawn at each time point during pharmacokinetic studies, in contrast to the clinical scenario, where large blood volumes (up to $3-5 \mathrm{ml}$ ) can be drawn at each time point. Hence there is a need to develop and validate an LC-MS/MS method using small volume of plasma for quantification of MEM. MEM exerts its pharmacological activity by blocking the various channels of NMDA receptors, a subfamily of glutamate receptor in brain and cerebro spinal fluid (CSF) ${ }^{3}$. Hence the present study was designed to assess the concentrations of MEM in brain and CSF which may help to use plasma as a surrogate for the estimation of MEM in brain and CSF after oral administration of MEM. The newly developed LC-MS/MS method is having advantages of utilizing small plasma volume $(25 \mu \mathrm{l})$, shorter run time $(3 \mathrm{~min})$ and higher sensitivity $(\sim 8$ fold over the reported lowest LLOQ considering low plasma volume for processing and low injection volume for analysis). The method was successfully used in a rat pharmacokinetic study and to assess the brainto-plasma and CSF-to-plasma concentration of MEM following oral administration of MEM at $5 \mathrm{mg} / \mathrm{kg}$ dose.

\section{MATERIALS AND METHODS}

\section{MATERIALS}

Memantine (purity 99.0\%) was sourced by Orchid Pharmaceuticals, Chennai and Phenacetin (Figure 1), purity 99.6\% was procured from Sigma-Aldrich (St. Louis, USA). HPLC-grade acetonitrile, methanol and analytical grade methyl tert-butyl methyl ether (TBME) were purchased from Rankem (Ranbaxy Fine Chemicals Limited, New Delhi, India). Analytical grade formic acid was purchased from S.D. Fine Chemicals (Mumbai, India). Disodium phosphate and tris- $\mathrm{HCl}$ buffer was purchased from Sigma-Aldrich (Milwaukee, WI, USA). The control rat plasma $\left(\mathrm{Na}_{2}\right.$.EDTA) was procured from our Animal House, Department of Pharmacology and stored at $-20 \pm 5^{\circ} \mathrm{C}$ prior to use.

\section{METHODS}

\section{Liquid Chromatography Conditions}

A Shimadzu VP (Shimadzu, Japan) LC system equipped with degasser (G1379A), quaternary pump (10ADvp), column oven (CTO-10ASvp), auto-sampler (SIL-HTC) along with system controller (SCL-10Avp) was used to inject $20 \mu \mathrm{l}$ aliquots of the processed samples on a Atlantis $\mathrm{dC}_{18}$ column $(50 \times 4.6 \mathrm{~mm}, 3 \mu \mathrm{m}$; Waters, Mil- 
ford, MA, USA), which was kept at ambient temperature $\left(24 \pm 2^{\circ} \mathrm{C}\right)$. The isocratic mobile phase, a mixture of $0.2 \%$ formic acid and acetonitrile mixture (40:60, $\mathrm{v} / \mathrm{v}$ ) was filtered through a $0.45 \mu \mathrm{m}$ membrane filter (XI5522050) (Millipore, USA or equivalent) and then degassed ultrasonically for 5 min was delivered at a flow rate of $0.50 \mathrm{ml} / \mathrm{min}$ into the mass spectrometer electro spray ionization chamber.

\section{Mass Spectrometry Operating Conditions}

Quantitation was achieved by LC-MS/MS detection in positive ion mode for analyte and IS using an MDS Sciex (Foster City, CA, USA) API 4000 mass spectrometer, equipped with a Turboionsprayä interface at $500^{\circ} \mathrm{C}$. The common parameters, i.e. curtain gas, nebulizer gas, auxillary gas and collision gas were set at 10, 30, 35 and 40 psi, respectively. The compounds parameters, i.e. declustering potential (DP), collision energy (CE), collision exit potential (CXP) and entrance potential (EP) for MEM and IS were 86, 21, 28, $10 \mathrm{~V}$ and 34, 30, 8, 10 $\mathrm{V}$, respectively. Detection of the ions was performed in the Multiple Reaction Monitoring (MRM) mode, monitoring the transition of the $m / z 180.10$ precursor ion to the $m / z 163.30$ product ion for MEM and $m / z$ 180.10 precursor ion to the $m / z 110.10$ product ion for IS. Quadrupole Q1 was set on low resolution where as Q3 was set on unit resolution. The analytical data were processed by Analyst software (version 1.5.2).

\section{Preparation of Stock and Standard Solutions}

Primary stock solutions of MEM for preparation of standard and quality control (QC) samples were prepared from separate weighing. The primary stock solutions $(1000 \mu \mathrm{g} / \mathrm{ml})$ of MEM and IS were made in methanol. The primary stock solutions were stored at $4^{\circ} \mathrm{C}$, which were found to be stable for one month (data not shown) and successively diluted with methanol to prepare working solutions to prepare calibration curve (CC). Another set of working stock solutions of MEM were made in methanol (from primary stock) for preparation of QC samples. Working stock solutions were stored approximately at $4^{\circ} \mathrm{C}$ for a week (data not shown). Appropriate dilutions of MEM stock solution was made in methanol to produce working stock solutions of $0.25,1.0,11.0,120,600,1201,1801$ and 2201 $\mathrm{ng} / \mathrm{mL}$ for CC and 0.25, 0.75, 1101 and $1601 \mathrm{ng} / \mathrm{mL}$ for QC. Working stocks were used to prepare plasma calibration standards. A working IS solution (50 ng/ $\mathrm{ml}$ ) was prepared in methanol. Calibration samples were prepared by spiking $22.5 \mu \mathrm{l}$ of control rat plasma with the appropriate working solution of the analyte $(2.5 \mu \mathrm{l})$ and IS $(5 \mu \mathrm{l})$ on the day of analysis. Samples for the determination of precision and accuracy were prepared by spiking control rat plasma in bulk with MEM at appropriate concentrations [0.025 ng/ml (LLOQ, lower limit of quantitation), $0.075 \mathrm{ng} / \mathrm{ml}$ (LQC, low quality control), $110 \mathrm{ng} / \mathrm{ml}$ (MQC, medium quality control) and $160 \mathrm{ng} / \mathrm{ml}$ (HQC, high quality control)] and $25 \mathrm{ml}$ plasma aliquots were distributed into different tubes. All the samples were stored at $-80 \pm 10^{\circ} \mathrm{C}$ until analysis.

\section{Recovery}

The efficiency of MEM and IS extraction from rat plasma was determined by comparing the responses of the analytes extracted from replicate QC samples $(n=$ $6)$ with the response of analytes from post extracted plasma standard sample at equivalent concentrations by liquid-liquid extraction process. Recovery of MEM was determined at LQC (0.075 ng/ml), MQC (110 ng/ $\mathrm{ml})$ and HQC $(160 \mathrm{ng} / \mathrm{ml})$ concentrations, whereas the recovery of the IS was determined at a single concentration of $50 \mathrm{ng} / \mathrm{ml}$.

\section{Sample Preparation}

A simple liquid-liquid extraction method was followed for extraction of MEM from rat plasma. To an aliquot of $25 \mu \mathrm{l}$ plasma, IS solution $(5 \mu \mathrm{l}$ of $50 \mathrm{ng} / \mathrm{ml}$ ) was added and mixed for $15 \mathrm{sec}$ on a cyclomixer (Remi Instruments, Mumbai, India). Added $100 \mu \mathrm{l}$ of $10 \mathrm{~mm}$ disodium phosphate buffer followed by adding $1.5 \mathrm{ml}$ of TBME, the mixture was vortexed for $5 \mathrm{~min}$; followed by centrifugation for $10 \mathrm{~min}$ at $10000 \mathrm{rpm}$ on Multifuge $3_{\mathrm{SR}}$ (Heraus, Germany). The organic layer $(1.4 \mathrm{~mL})$ was separated and evaporated to dryness at $40^{\circ} \mathrm{C}$ using a gentle stream of nitrogen (TurbovapÒ, ZymarkÒ Kopkinton, MA, USA). The residue was reconstituted in $150 \mu \mathrm{l}$ of the mobile phase and $20 \mu \mathrm{l}$ was injected onto LC-MS/MS system.

\section{Method Validation Procedures}

A full validation according to the US FDA guidelines ${ }^{14}$ was performed for the assay in rat plasma.

\section{Specificity and Selectivity}

The specificity of the method was evaluated by analyzing rat plasma samples from at least six different lots to investigate the potential interferences at the LC peak region for analyte and IS.

\section{Matrix Effect}

The effect of rat plasma constituents over the ionization of MEM and IS was determined by post column infusion method to evaluate matrix effect. ${ }^{15}$ Briefly, an infusion pump delivers a constant amount of analyte in to LC system outlet entering to mass spectrometer inlet. Mass spectrometer was operated in MRM mode to follow the analyte signal. Rat plasma constituents sample extract was injected on LC column under same chro- 
matographic condition. Since the analyte was infused at constant rate, a steady ion response was obtained as a function of time. Any endogenous compound that elutes from the column and causes a variation in ESI (Electro Spray Ionization) response of the infused analyte was seen as a suppression or enhancement in the response of the infused analyte. In addition to post column infusion method, to further evaluate matrix effect, six different lots of rat plasma were spiked with analyte concentration levels at LQC, MQC and HQC levels. The acceptance criteria for each back-calculated concentration were $\pm 15 \%$ deviation from the nominal value except at LLOQ, which was set at $\pm 20 \%$.

\section{Calibration Curve}

The eight point calibration curve $(0.025,0.10,1.10,12.0$, 60.0, 120.1, 180.1 and $220.1 \mathrm{ng} / \mathrm{ml}$ ) was constructed by plotting the peak area ratio of MEM:IS against the nominal concentration of calibration standards in rat plasma. Following the evaluation of different weighting factors, the results were fitted to linear regression analysis with the use of $1 / X^{2}$ (X-concentration) weighting factor. The calibration curve had to have a correlation coefficient $(r)$ of 0.99 or better. The acceptance criteria for each back-calculated standard concentration were \pm $15 \%$ deviation from the nominal value except at LLOQ, which was set at $\pm 20 \%{ }^{14}$

\section{Precision and Accuracy}

The intra-assay precision and accuracy were estimated by analyzing six replicates containing MEM at four different QC levels i.e., 0.025 (LLOQ), 0.075 (LQC), 110 (MQC) and $160 \mathrm{ng} / \mathrm{ml}$ (HQC) in plasma. The interassay precision was determined by analyzing the four levels QC samples on four different runs. The criteria for acceptability of the data included accuracy within $\pm 15 \%$ deviation (SD) from the nominal values and a precision of within $\pm 15 \%$ relative standard deviation (RSD) except for LLOQ, where it should not exceed \pm $20 \%$ of SD. ${ }^{14}$

\section{Stability Experiments}

The stability of MEM and IS in the injection solvent was determined periodically by injecting replicate preparations of processed plasma homogenate samples for up to $24 \mathrm{~h}$ (in the auto sampler at $10^{\circ} \mathrm{C}$ ) after the initial injection. The peak-areas of the analyte and IS obtained at initial cycle were used as the reference to determine the stability at subsequent points. Stability of MEM in the biomatrix during $6 \mathrm{~h}$ (bench-top) was determined at ambient temperature $\left(25 \pm 2^{\circ} \mathrm{C}\right)$ at two concentrations $(0.075$ and $160 \mathrm{ng} / \mathrm{ml})$ in six replicates. Freezer stability of MEM in rat plasma was assessed by analyzing the LQC and HQC samples stored at $-80 \pm 10^{\circ} \mathrm{C}$ for at least 30 days. The stability of MEM in rat plasma following three freeze-thaw cycles was assessed using QC samples spiked with MEM. The samples were stored at $-80 \pm 10^{\circ} \mathrm{C}$ between freeze/thaw cycles for at least 12 $\mathrm{h}$ for each cycle. The samples were thawed by allowing them to stand (unassisted) at room temperature for approximately $2 \mathrm{~h}$. The samples were then returned to the freezer. The samples were processed using the same procedure as described in the sample preparation section. Samples were considered stable if assay values were within the acceptable limits of accuracy (i.e., $85-115 \%$ from fresh samples) and precision (i.e., $\pm 15 \%$ RSD). ${ }^{14}$

\section{Dilution Effect}

Dilution effect was investigated to ensure that samples could be diluted with blank matrix without affecting the final concentration. MEM spiked rat plasma samples prepared at two concentrations (100 and $3001 \mathrm{ng} / \mathrm{ml}$ ) of MEM were diluted with pooled rat plasma at dilution factors of 5 and 10 in six replicates and analyzed. As part of validation, the replicates had to comply to have both precision of $\leq 15 \%$ and accuracy of $100 \pm 15 \%$ similar to other QC samples. ${ }^{14}$

\section{Incurred Samples Reanalysis (ISR)}

The recent guidelines have emphasized on the necessity of ensuring incurred sample reproducibility. ${ }^{16}$ As per the guidance the difference in concentrations between the initial value and the ISR should be less than $\pm 20 \%$ of their means for at least $67 \%$ of the repeats. Large difference between results may indicate analytical issues and should be investigated. We have selected the samples for reanalysis from $\mathrm{C}_{\max }$ and elimination phase time points. In total 48 samples out of 18 samples were reanalyzed under a separate batch.

$\%$ Change $=\frac{\text { Repeat value }- \text { Initial value }}{\text { Mean of repeat and initial values }} \times 100$

\section{Pharmacokinetic Study in Rats}

Male Sprague Dawley rats were quarantined in our animal house for a period of 7 days with a $12 \mathrm{~h}$ dark/ light cycle and during this period they had free access to standard pellet feed and water ad libitum. The protocol of the animal experiments was submitted to the Committee for the Purpose of Control and Supervision of Experimentation on Animals (CPCSEA) and was approved by duly constituted the Institutional Animal Ethics Committee. For all the experimental work, animals were kept on a $12 \mathrm{~h}$ overnight fast and had access to water ad libitum. Feed was provided $2 \mathrm{~h}$ post-dose of MEM administration and water was allowed ad libitum. 
Following overnight fast, animals were divided into three groups. Group I and II animals $(n=4$ for each study, weight range: $210-220 \mathrm{~g}$ ) were dose with MEM orally (in the form of a suspension, prepared using $0.5 \%$ methyl cellulose + Tween-80) and intravenously (i.v, using solution formulation comprising $10 \%$ DMSO and $90 \%$ normal saline) at 5.0 and $1.0 \mathrm{mg} / \mathrm{kg}$, respectively. Post-dosing blood samples $(75 \mu \mathrm{l}$ at each time point) were drawn into Polypropylene tubes containing $\mathrm{Na}_{2}$.EDTA solution as an anti-coagulant at pre-dose, 0.12 (i.v only), $0.25,0.5,1,2,4,8,10$ (oral only) and 24 h. Group III animals ( $n=9$, weight range: $212-225 \mathrm{~g}$ ) also received $5 \mathrm{mg} / \mathrm{kg}$ of MEM orally (using suspension formulation) and blood samples along with CSF and brain tissue were collected at 0.5, 2 and $4 \mathrm{~h}$.

Plasma was harvested by centrifuging the blood using Eppendorf 5430R Centrifuge (Germany) at $5000 \mathrm{rpm}$ for $5 \mathrm{~min}$ and stored frozen at $-80 \pm 10^{\circ} \mathrm{C}$ until analysis. After collection of CSF it was stored at $-80+10^{\circ} \mathrm{C}$ until analysis. Following the collection of brain tissue in a $15 \mathrm{ml}$ round bottom screw capped vial, Tris- $\mathrm{HCl}$ buffer $(4.0 \mathrm{~mL})$ was added and homogenated with a homogenizer (Miccra D-9) and stored frozen at $-80 \pm 10^{\circ} \mathrm{C}$ until analysis. Plasma $(25 \mu \mathrm{l})$ or CSF $(25 \mu \mathrm{l})$ or brain homogenate $(200 \mu \mathrm{l})$ samples were spiked with IS and processed as mentioned in sample preparation section.

Along with PK samples at LQC, MQC and HQC were assayed in duplicate and were distributed among unknown samples in the analytical run. The criteria for acceptance of the analytical runs encompassed the following: (i) 67\% of the QC samples accuracy must be within $85-115 \%$ of the nominal concentration (ii) not less than $50 \%$ at each QC concentration level must meet the acceptance criteria. Plasma concentration-time data of MEM was analyzed by non-compartmental method using WinNonlin Version 5.3 (Pharsight Corporation, Mountain View, CA).

\section{RESULTS AND DISCUSSION}

\section{Optimization of Liquid Chromatography and Mass Spectrometry Conditions}

Feasibility of various mixture(s) of solvents such as acetonitrile and methanol using different buffers such as ammonium acetate, ammonium formate, trifluoroacetic acid and formic acid along with altered flow-rates (in the range of 0.4-0.8 $\mathrm{ml} / \mathrm{min}$ ) were tested for complete chromatographic resolution of MEM and IS (data not shown). The resolution of peaks was achieved with $0.2 \%$ formic acid:acetonitrile $(40: 60, \mathrm{v} / \mathrm{v})$ with a flow rate of $0.50 \mathrm{~mL} / \mathrm{min}$, on an Atlantis $\mathrm{dC}_{18}$ column $(50 \times 4.6 \mathrm{~mm}$, $3 \mu \mathrm{m}$; Waters, Milford, MA, USA) and was found to be suitable for the determination of electrospray response for MEM and IS.

In order to optimize ESI conditions for MEM and IS, quadrupole full scans were carried out in positive ion detection mode. During a direct infusion experiment, the mass spectra for MEM and IS revealed peaks at $\mathrm{m} / \mathrm{z}$ 180.10 and 180.10 , respectively, as protonated molecular ions, $[\mathrm{M}+\mathrm{H}]^{+}$. Following detailed optimization of mass spectrometry conditions (provided in Mass Spectrometry Operating Conditions section) $\mathrm{m} / \mathrm{z} 180.10$ precursor ion to the $\mathrm{m} / z_{1} 163.30$ was used for quantification for MEM. Similarly, for IS $m / z 180.10$ precursor ion to the $m / z 110.10$ was used for quantification purpose. As the earlier publications ${ }^{6-8}$ have discussed extensively on fragmentation pattern of MEM and the data pertaining to this was not presented here.

\section{Recovery}

A simple liquid-liquid extraction method proved to be robust and provided cleanest samples. The results of the comparison of neat standards versus plasma-extracted standards were estimated for MEM. The mean recovery was found to be $72.3 \pm 1.26,73.9 \pm 1.80$ and 68.8 $\pm 4.07 \%$ at 0.075 (LQC), 110 (MQC) and $160 \mathrm{ng} / \mathrm{ml}$ (HQC), respectively (Table 1). The recovery of IS at $50.0 \mathrm{ng} / \mathrm{ml}$ was $83.5 \pm 1.17 \%$.

\section{Matrix Effect}

Figures $2 \mathrm{~A}$ represents the matrix effect (rat plasma) chromatogram overlaid by aqueous standard chromatogram to indicate the elution profile for the analyte over the analyte infusion matrix effect baseline for MEM and IS, respectively. No significant signal suppression was observed in the region of elution of MEM and IS, respectively. Six different lots of rat plasma, spiked with analyte concentration levels at LQC, MQC and HQC levels were analyzed. The results have shown that the precision and accuracy for analyzed samples were within acceptance range (Table 1). Overall it was found that there is no impact on the ionization of analyte and IS.

\section{Method Validation Parameters}

\section{Specificity and Selectivity}

Figures 3A-D shows a typical chromatogram for the blank rat plasma (free of analyte and IS; Figure 3A), blank rat plasma spiked with IS (Figure 3B), blank rat plasma spiked with MEM at LLOQ and IS (Figure 3C) and an in vivo plasma sample obtained at $0.5 \mathrm{~h}$ after oral administration of MEM (Figure 3D). No interfering peaks from endogenous compounds are observed at the retention times of analyte and IS in the matrix. The retention time of MEM and IS was $\sim 1.0$ and $1.83 \mathrm{~min}$, 
A
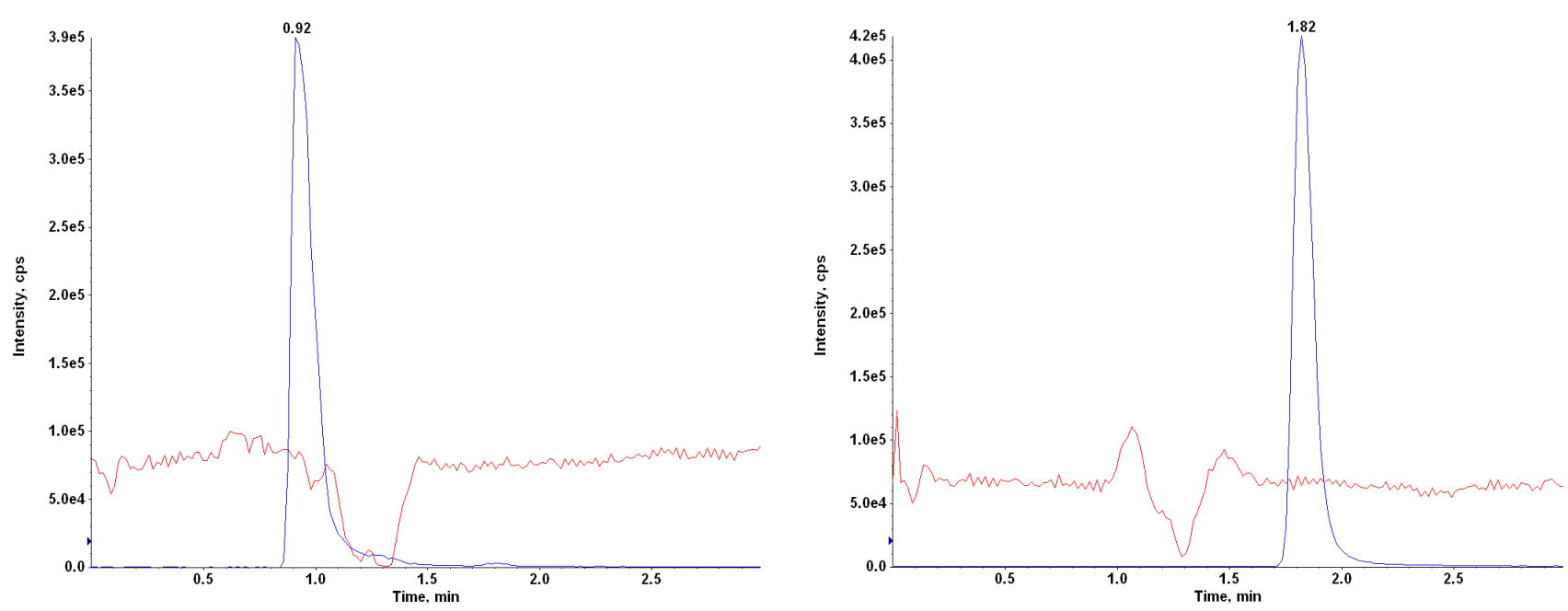

B
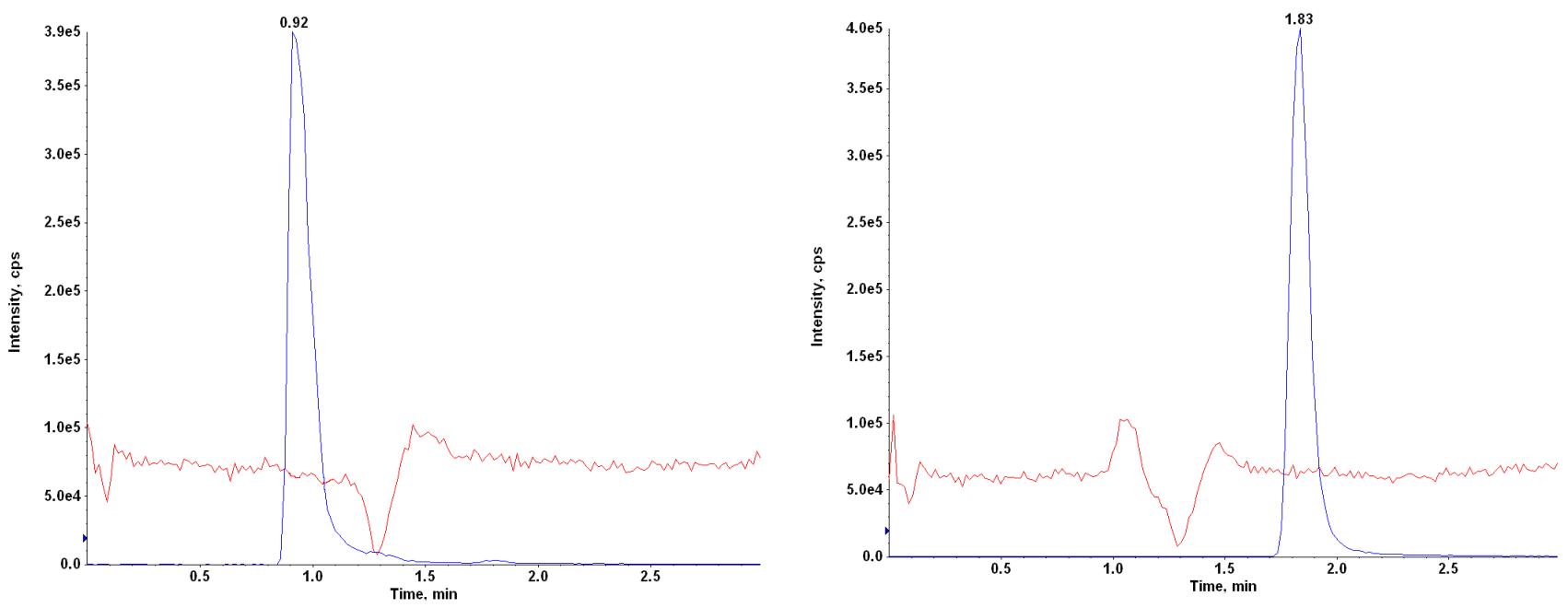

C
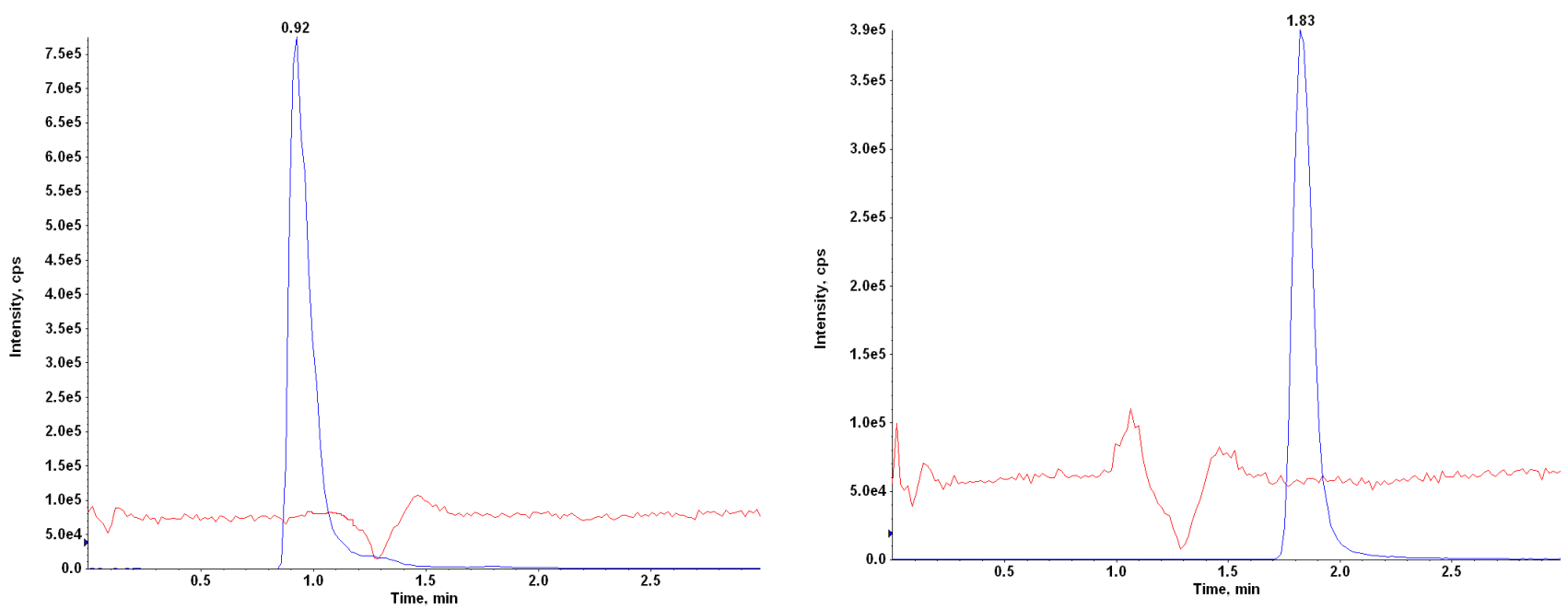

Figure 2. Overlay chromatograms showing the matrix effect for MEM (left panel) and IS (right panel in rat blank (A) plasma (B) brain homogenate and (C) CSF 
Table 1. Recovery and matrix effect of MEM at low, middle and high quality control level

\begin{tabular}{ccc} 
& $\begin{array}{c}\text { Mean recovery (\%) } \\
\text { Mean } \pm \text { SD }(\boldsymbol{n}=\mathbf{4})\end{array}$ & $\begin{array}{c}\text { Mean absolute matrix effect } \\
\text { Mean } \pm \text { SD }(\boldsymbol{n}=\mathbf{4})\end{array}$ \\
\hline $\begin{array}{c}\text { LQC } \\
(0.075 \mathrm{ng} / \mathrm{ml}) \\
\text { MQC } \\
(110 \mathrm{ng} / \mathrm{ml}) \\
\mathrm{HQC}\end{array}$ & $72.3( \pm 1.26)$ & $97.8( \pm 0.19)$ \\
$(160 \mathrm{ng} / \mathrm{ml})$ & $73.9( \pm 1.80)$ & $96.6( \pm 0.21)$ \\
\hline
\end{tabular}

respectively. The total chromatographic run time was $3.0 \mathrm{~min}$. The specificity of the method was evaluated by analyzing rat plasma samples from six different animals to investigate the potential interferences at the LC peak region for analyte and IS. No significant response was observed in the LC region for any of the blank samples analyzed; as compared to corresponding LLOQ level response in same matrix lot (data not shown) and the $\%$ RSD was found to be 0.001 and $\%$ RE 6.15 .

\section{Calibration Curve}

The plasma calibration curve was constructed using eight calibration standards (viz., $0.025-220 \mathrm{ng} / \mathrm{ml}$ ). The calibration standard curve had a reliable reproducibility over the standard concentrations across the calibration range. Calibration curve was prepared by determining the best fit of peak-area ratios (peak area analyte/peak area IS) versus concentration, and fitted to the $y=m x+$ $c$ using weighting factor $\left(1 / X^{2}\right)$. The average regression $(n=4)$ was found to be $\geq 0.999$. The $\% \mathrm{RSD}$ and $\% \mathrm{RE}$ of slope and intercept was $5.23 \pm 9.97$ and $8.93 \pm 0.78$, respectively. The lowest concentration with the RSD < $20 \%$ was taken as LLOQ and was found to be $0.025 \mathrm{ng} /$ $\mathrm{ml}$. The \% accuracy observed for the mean of backcalculated concentrations for four calibration curves for MEM was within 92.9-103; while the precision (\% CV) values ranged from 1.15-5.15.

A
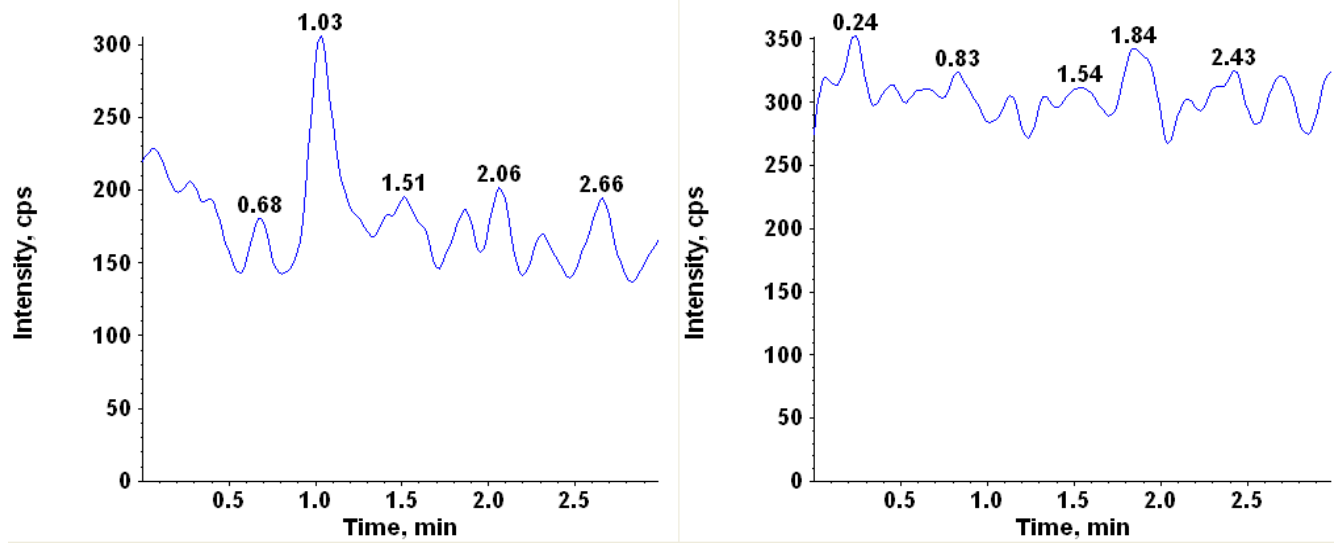

B
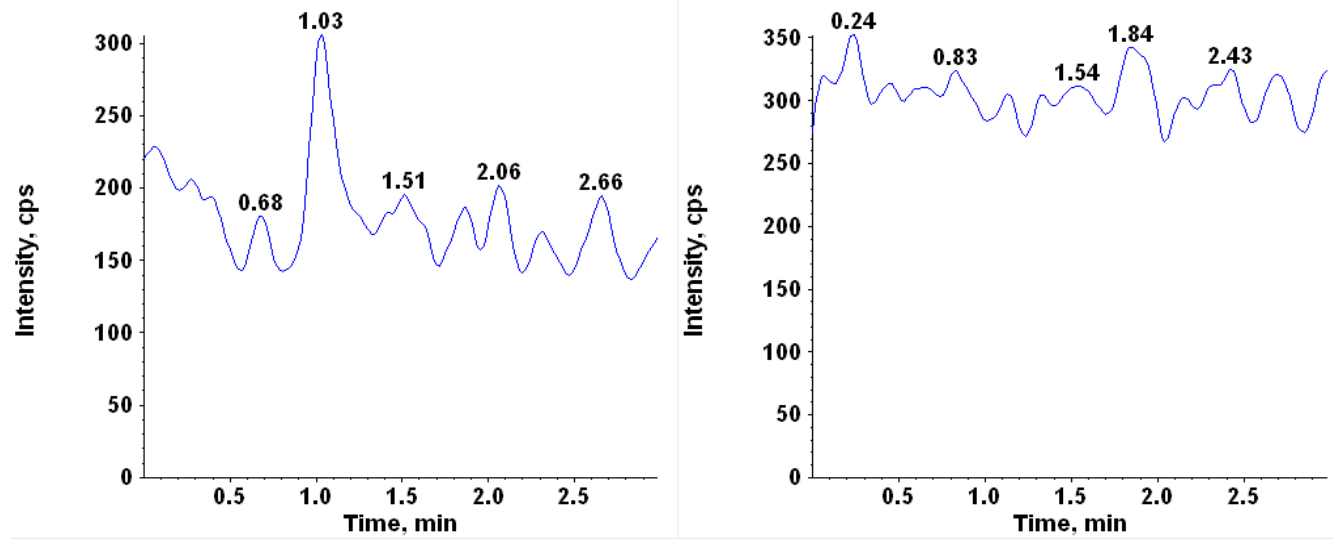

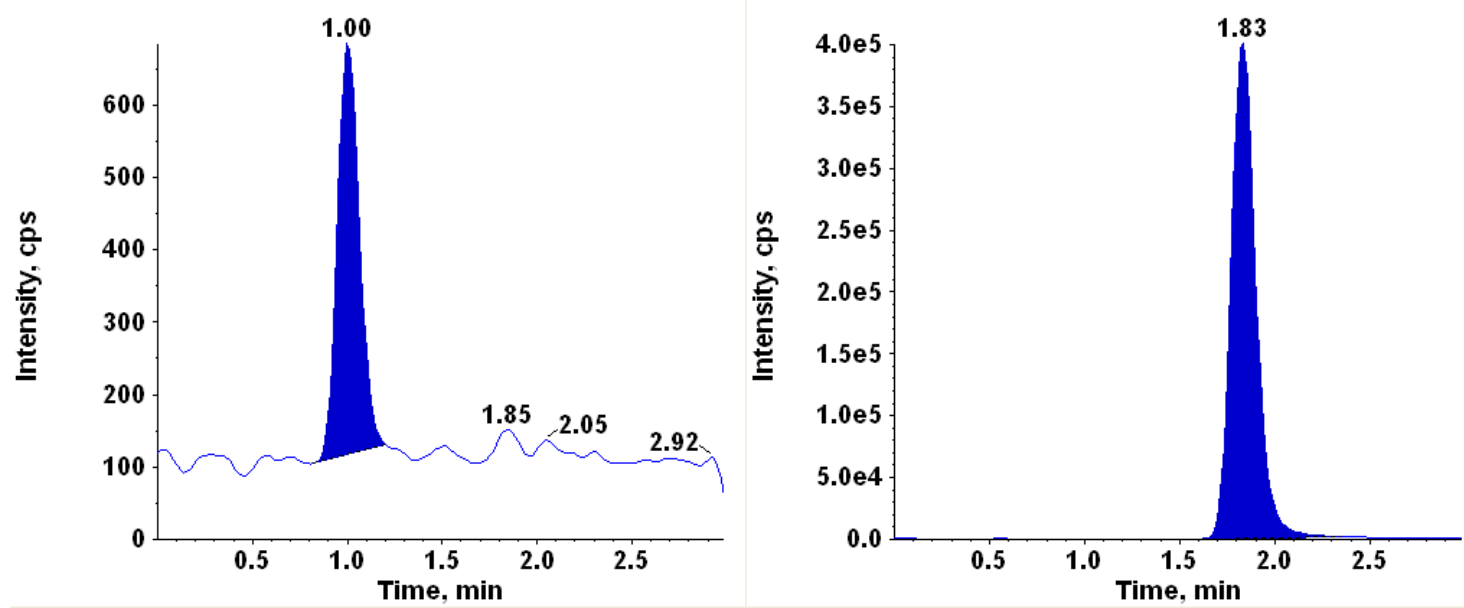

D
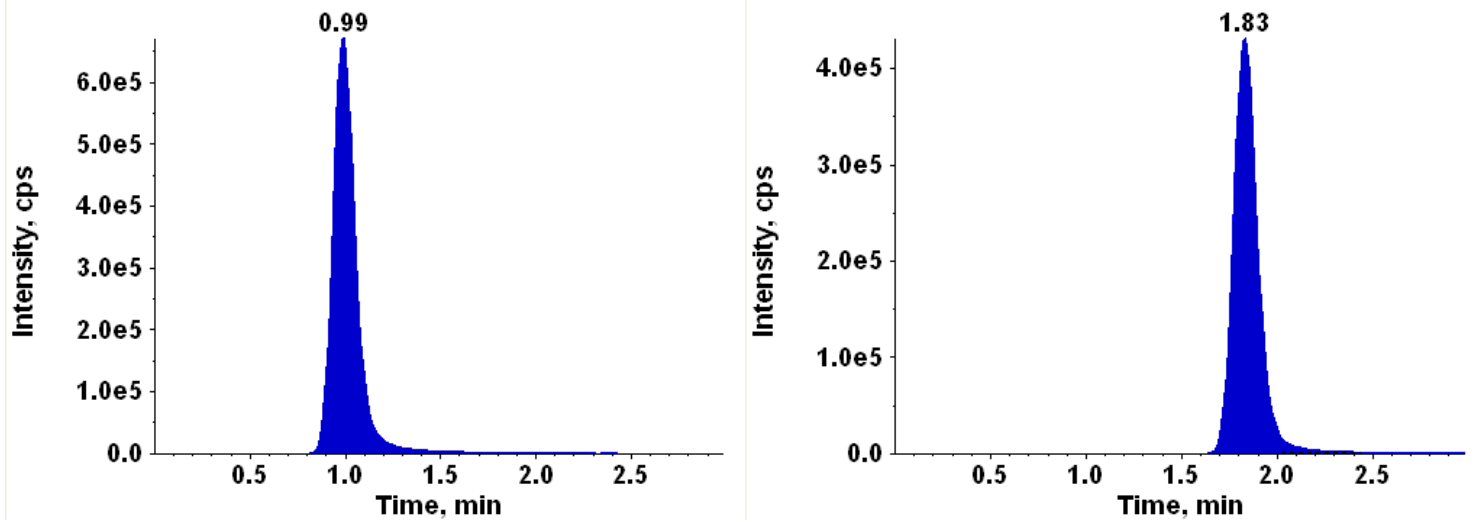

Figure 3. Typical MRM chromatograms of MEM (left panel) and IS (right panel) in (A) rat blank plasma (B) rat plasma spiked with IS (C) rat plasma spiked with MEM at LLOQ $(0.025 \mathrm{ng} / \mathrm{ml})$ and (D) a $0.5 \mathrm{~h}$ plasma sample showing MEM (200 $\mathrm{ng} / \mathrm{ml}) \mathrm{peak}$ obtained following $5 \mathrm{mg} / \mathrm{kg}$ oral dose of MEM to rats.

\section{Accuracy and Precision}

Accuracy and precision data for intra-day and inter-day plasma homogenate samples are presented in (Table 2). The assay values on both the occasions (intra- and inter-day) were found to be within the accepted variable limits.

\section{Stability}

The predicted concentrations for MEM at 0.075 and $160 \mathrm{ng} / \mathrm{ml}$ samples deviated within $\pm 15 \%$ of the nominal concentrations in a battery of stability tests viz., ininjector $(24 \mathrm{~h})$, bench-top $(6 \mathrm{~h})$, repeated three freeze/ thaw cycles and freezer stability at $-80 \pm 10^{\circ} \mathrm{C}$ for at least for 30 days (Table 3 ). The results were found to be within the assay variability limits during the entire process.

\section{Dilution Effect}

Standard curve can be extended up to $3001 \mathrm{ng} / \mathrm{ml}$ without affecting the final concentrations. The results have shown that the precision and accuracy for six replicates of diluted samples were within the acceptance range (data not shown).

\section{Incurred Samples Reanalysis (ISR)}

All the 18 samples selected for ISR met the acceptance criteria. The back calculated accuracy values ranged between 80.2 to $108 \%$.

\section{Pharmacokinetic Study in Rats}

The sensitivity and specificity of the assay were found to be sufficient for accurately characterizing the plasma pharmacokinetics of MEM in rats. Profiles of the mean 
Table 2. Intra-day and inter-day precision of determination of MEM in rat plasma

\begin{tabular}{|c|c|c|c|c|c|}
\hline \multirow{2}{*}{$\begin{array}{c}\text { Theoretical } \\
\text { concentration } \\
\text { (ng/ml) }\end{array}$} & \multirow{2}{*}{ Run } & \multicolumn{4}{|c|}{ Measured concentration (ng/ml) } \\
\hline & & Mean & SD & RSD & $\begin{array}{c}\text { Accuracy } \\
(\%)\end{array}$ \\
\hline \multicolumn{6}{|c|}{ Intra day variation (Six replicates at each concentration) } \\
\hline \multirow{4}{*}{0.025} & 1 & 0.022 & 0.002 & 6.84 & 89.3 \\
\hline & 2 & 0.024 & 0.001 & 3.01 & 94.0 \\
\hline & 3 & 0.024 & 0.002 & 6.45 & 85.0 \\
\hline & 4 & 0.022 & 0.002 & 6.11 & 88.0 \\
\hline \multirow{4}{*}{0.075} & 1 & 0.072 & 0.003 & 3.98 & 96.3 \\
\hline & 2 & 0.072 & 0.002 & 2.78 & 96.0 \\
\hline & 3 & 0.071 & 0.002 & 3.04 & 94.7 \\
\hline & 4 & 0.074 & 0.002 & 2.67 & 98.7 \\
\hline \multirow{4}{*}{110} & 1 & 116 & 2.24 & 1.93 & 105 \\
\hline & 2 & 114 & 3.12 & 2.73 & 104 \\
\hline & 3 & 111 & 0.98 & 0.88 & 101 \\
\hline & 4 & 110 & 0.88 & 0.80 & 100 \\
\hline \multirow{4}{*}{160} & 1 & 180 & 8.70 & 4.82 & 113 \\
\hline & 2 & 165 & 2.43 & 1.47 & 103 \\
\hline & 3 & 157 & 3.00 & 1.91 & 97.9 \\
\hline & 4 & 154 & 2.76 & 1.72 & 96.0 \\
\hline \multicolumn{6}{|c|}{ Inter day variation (Twenty four replicates at each concentration) } \\
\hline 0.025 & & 0.023 & 0.001 & 5.86 & 92.5 \\
\hline 0.075 & & 0.072 & 0.002 & 3.12 & 99.3 \\
\hline 110 & & 114 & 2.92 & 2.57 & 103 \\
\hline 160 & & 167 & 11.4 & 6.79 & 105 \\
\hline
\end{tabular}

RSD: Relative standard deviation (SD x 100/Mean)

Table 3: Stability data MEM quality controls in rat plasma

\begin{tabular}{|c|c|c|c|c|}
\hline $\begin{array}{c}\text { Nominal } \\
\text { concentration } \\
(\mathrm{ng} / \mathrm{ml})\end{array}$ & Stability & $\begin{array}{c}\text { Mean } \pm S D^{a} \\
n=6 \\
(n g / m l)\end{array}$ & $\begin{array}{c}\text { Accuracy } \\
(\%)^{b}\end{array}$ & $\begin{array}{c}\text { Precision } \\
\text { (\% CV) }\end{array}$ \\
\hline \multirow{5}{*}{0.075} & $0 \mathrm{~h}$ (for all) & $0.072 \pm 0.003$ & 96.3 & 3.98 \\
\hline & 3rd freeze-thaw & $0.071 \pm 0.003$ & 94.7 & 3.73 \\
\hline & $6 \mathrm{~h}$ (bench-top) & $0.072 \pm 0.003$ & 96.4 & 4.22 \\
\hline & $24 \mathrm{~h}$ (in-injector) & $0.071 \pm 0.003$ & 94.7 & 4.23 \\
\hline & 30 days at $-80^{\circ} \mathrm{C}$ & $0.073 \pm 0.002$ & 96.7 & 2.86 \\
\hline \multirow{5}{*}{160} & $\mathrm{O} \mathrm{h}$ (for all) & $157 \pm 3.00$ & 97.9 & 1.91 \\
\hline & 3rd freeze-thaw & $162 \pm 1.69$ & 101 & 1.05 \\
\hline & $6 \mathrm{~h}$ (bench-top) & $172 \pm 11.2$ & 108 & 6.50 \\
\hline & $24 \mathrm{~h}$ (in-injector) & $177 \pm 4.97$ & 111 & 2.81 \\
\hline & 30 days at $-80^{\circ} \mathrm{C}$ & $160 \pm 2.29$ & 99.9 & 1.43 \\
\hline
\end{tabular}

${ }^{a}$ Back-calculated plasma concentrations; ' ${ }^{(M e a n}$ assayed concentration/mean assayed concentration at $\left.0 \mathrm{~h}\right) \mathrm{x} 100$. 
plasma concentration versus time were shown in Figure 4. MEM was quantifiable up to $24 \mathrm{~h}$ following oral and $i . v$ administration because of higher sensitivity of the present method. Post-dosing quantitation of any drug during terminal phase for extended time points is very critical to derive key pharmacokinetic parameters like half-life, clearance and volume of distribution etc. Keeping this in mind we have developed and validated a highly sensitive method $(0.025 \mathrm{ng} / \mathrm{ml}$ using $25 \mu \mathrm{l}$ of plasma) for quantification of MEM in low volume of biological matrices, which will be extremely useful for preclinical species pharmacokinetic and toxicokinetic work.

In the present study following i.v administration the clearance $(\mathrm{Cl})$ and volume of distribution $(\mathrm{Vd})$ were found to be $53.3 \pm 17.6 \mathrm{ml} / \mathrm{min} / \mathrm{kg}$ and $23.4 \pm 15.4$ $\mathrm{L} / \mathrm{kg}$, respectively. The $\mathrm{AUC}_{0-¥}$ (area under the plasma concentration-time curve from time zero to infinity) was found to be $892 \pm 171$ and $333 \pm 92.3 \mathrm{ng}_{*} \mathrm{~h} / \mathrm{ml}$, by oral and $i . v$ routes, respectively. The terminal half-life $\left(\mathrm{t}_{1 / 2}\right)$ was $4.75 \pm 1.51$ and $3.46 \pm 0.65 \mathrm{~h}$ by $i . v$ and oral route, respectively. The absolute oral bioavailability was $53.5 \%$.

Although, full validation of MEM in CSF and brain homogenate was not performed, the recovery of MEM at 0.075 (LQC), 110 (MQC) and $160 \mathrm{ng} / \mathrm{ml}$ (HQC) was found to be $65.3 \pm 9.56,68.9 \pm 5.27$ and $66.5 \pm 7.24 \%$, respectively in CSF and $67.4 \pm 12.0,72.0 \pm 5.07$ and $77.1 \pm 1.65 \%$, respectively in brain homogenate using the similar extraction process used for plasma. The percentage accuracy observed for the mean of backcalculated concentrations for two calibration curves for MEM in CSF and brain homogenate was within acceptable limits (data not shown). Hence the plasma calibration curve was used to quantitate the CSF and brain concentrations following oral dosing of MEM to rats. The QCs spiked in CSF and brain homogenate met the acceptance criteria (data not shown) when the con-

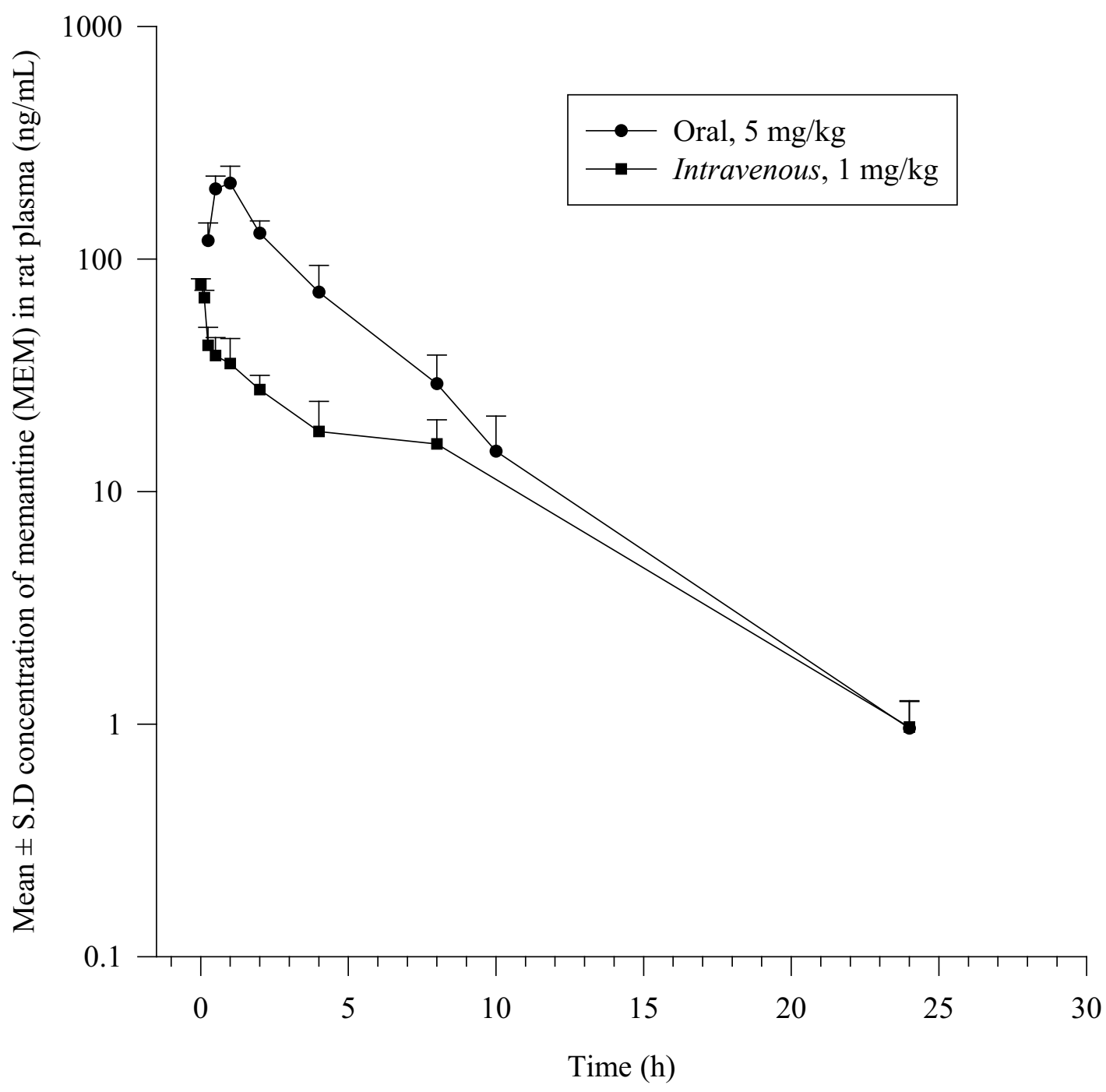

Figure 4. Mean \pm SD plasma concentration-time profile of MEM in rat plasma following intravenous and oral dosing of MEM to rats 


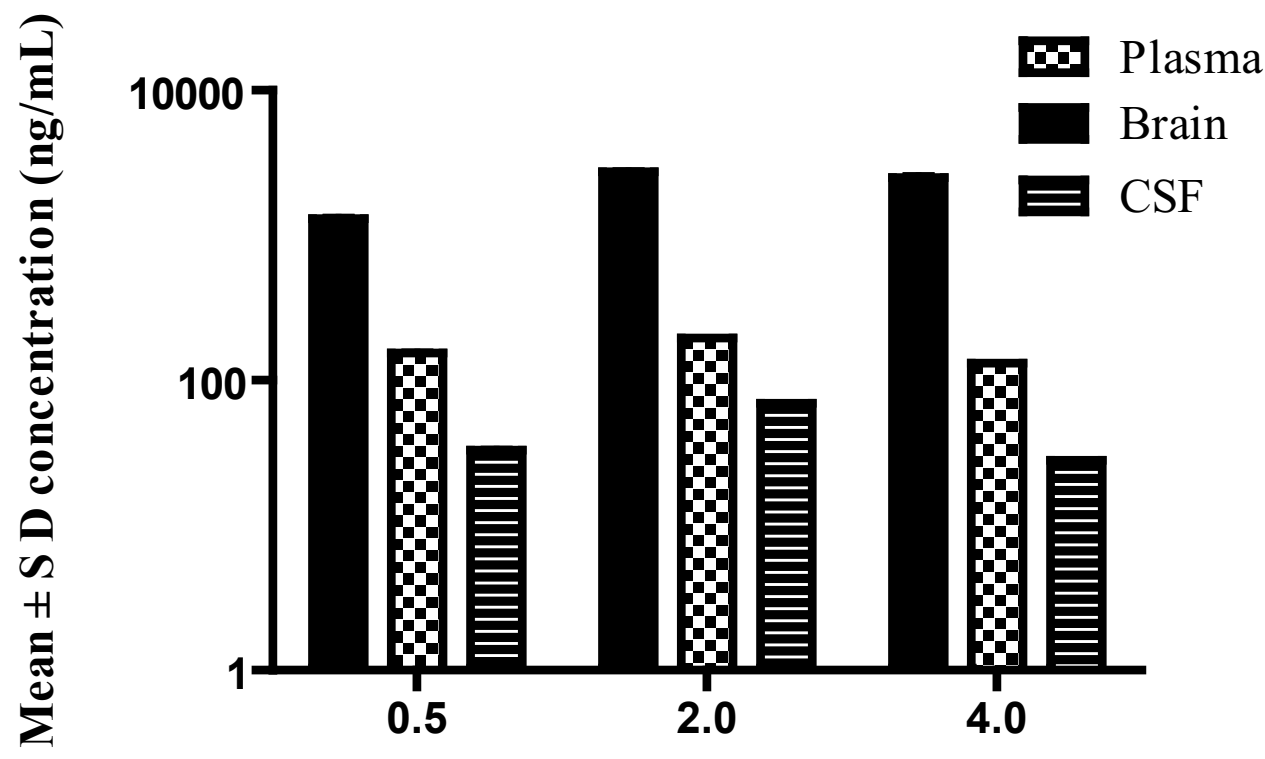

\section{Time (h)}

Figure 5 Brain-to-plasma and brain-to-CSF ratio of MEM at $0.5,2$ and $4 \mathrm{~h}$ following oral administration of MEM to rats.

centrations were back-calculated using plasma linearity. Further, there was no interference from the MEM free $\mathrm{CSF}$ and brain homogenate (collected from four rats) at the retention times of analyte and IS (Figures 2B and $2 \mathrm{C}$ ). Figure 5 shows the brain-to-plasma and brainto-CSF ratio at $0.5,2$ and $4 \mathrm{~h}$ time points. The brainto-plasma ratio profile established by us will help the scientists to consider plasma as a surrogate to speculate the brain concentrations.

\section{CONCLUSION}

A method using LC-ESI-MS/MS for the determination of MEM in rat plasma employing simple liquidliquid extraction was developed. The method is rapid, simple, specific, and sensitive and additionally demonstrates good accuracy and precision. Compared to the published methods, the present method is featured with high selectivity and sensitivity with an LLOQ of $0.025 \mathrm{ng} / \mathrm{ml}$. This method can serve as a useful tool for the determination of MEM in plasma. The validated method was successfully applied to a rat pharmacokinetic study also to assess the brain-to-CSF ratio and brain-to-plasma ratio. Further studies in this method will extend the application to clinical pharmacokinetics, as this method considerably decreases the bio-burden on the volunteers, by reducing the withdrawal volume of blood samples.

\section{ACKNOWLEDGEMENT}

SPS and SSK thank VISTAS management for their encouragement.

\section{CONFLICT OF INTEREST}

Authors have no conflict of interest.

\section{REFERENCES}

1. Rogawski MA, Wenk GL. The neuropharmacological basis for the use of memantine in the treatment of Alzheimer's disease. CNS Drug Rev. 2003; 9(3): 275-308.

2. Reisberg B, Doody R, Stoffler A, Schmitt F, Ferris S, Mobius HJ. Memantine study group. Memantine in moderate to severe Alzheimer's disease. $\mathrm{N}$ Engl J Med. 2003; 348(14): 1333-41.

3. Johnson JW, Kotermanski SE. Mechanism of action of memantine. Curr Opin Pharmacol. 2006; 6(1): 61-7.

4. European Medicines Agency. Ebixa. European Public AssessNeuroproment Report. [online]. Jul 2002. Available from: http://www. emea.eu.int/humandocs/PDFs/EPAR/ebixa

5. Periclou A, Ventura D, Rao N, Abramowitz W. Pharmacokinetic study of memantine in healthy and renally impaired subjects. Clin Pharmacol Ther. 2006; 79(1): 134-43.

6. Konda RK, Challa BR, Chandu BR, Chandrasekhar KB. Bioanalytical method development and validation of memantine in human plasma by high performance liquid chromatography with tandem mass spectrometry: application to bioequivalence study. J Anal Methods Chem. 2012; 2012: 101249.

7. Almeida AA, Campos DR, Bernasconi G, Calafatti S, Barros FA, Eberlin MN, et al. Determination of memantine in human plasma by liquid chromatography electrospray tandem mass spectrometry: application to a bioequivalence study. J Chromatogr. B 2007; 848(2): 311-6. 
8. Pan RN, Chian TY, Kuo BPC, Pao LH. Determination of memantine in human plasma by LC-MS-MS. application to a pharmacokinetic study. Chromatographia. 2009; 70(5-6): 783-8.

9. Liu MY, Meng SN, Wu HZ, Wang S, Wei MJ. Pharmacokinetics of single-dose memantine in healthy Chinese volunteers using an analytic method of liquid chromatography tandem mass spectrometry. Clin Ther. 2008; 30(4): 641-53.

10. Karthikeyan S, Aji A, Singh S, Puthil SP. An LC-MS/MS method for the quantification of memantine in human plasma: development, validation and application to a pharmacokinetic study. Int J Pharm Biol Sci. 2013; 3(2): 343-54.

11. Noetzli M, Ansermot N, Dobrinas M, Eap CB. Simultaneous determination of antidementia drugs in human plasma: procedure transfer from HPLC-MS to UPLC-MS/MS. J Pharm Biomed Anal. 2012; 64(5):16-25.

12. Lou HG, Yu LY, Ruan ZR, Jiang B, Chen JL. Quantitative determination of memantine in human plasma by liquid chromatography tandem mass spectrometry: application to a bioequivalence study. J Liquid Chromatogr Related Technol. 2012; 35(19): 2696-705.

13. Liu W, Bi K, Liu X, Zhao J, Chen X. Cloud-point extraction combined with LC-MS for analysis of memantine in rat plasma. Chromatographia. 2009; 69(9-10): 837-42.

14. US DHHS, FDA, CDER. Guidance for Industry: Bioanalytical Method Validation. U.S. Department of Health and Human Services. Food and Drug Administration, Center for Drug Evaluation and Research (CDER), Center for Veterinary Medicine (CV), Rockville, MD, USA; 2001.

15. Bonfiglio R, King RC, Olah TV, Merkle K. The effects of sample preparation methods on the variability of the electrospray ionization response for model drug compounds. Rapid Commu Mass Spectrom. 1999; 13(12): 1175-85.

16. European Medicines Agency. Guideline on validation of bioanalytical methods. http://www.ema.europa.eu; 2010. 